\title{
Concerning the Types of Mallophora Rex and Cheysomela Bromley
}

In the June 1925 number of Psyche Vol. 32, p. 190, Mr. S. W. Bromley described two new species of Mallophora, in part, on material from the collection of The Academy of Natural Sciences of Philadelphia. He however, did not designate any type specimens, and as the material returned to the Academy was labeled types, I take this opportunity to record his type fixation as follows:

Mallophora rex Bromley. Type, male; Southern Pines, South Carolina, August 26, 1909. [Academy Collection, No. 6297].

Mallophora chrysomela Bromley. Type, male; Atlanta, Georgia, June 30, 1906, [Academy Collection, No. 6298].

E. T. Cresson, Jr. 

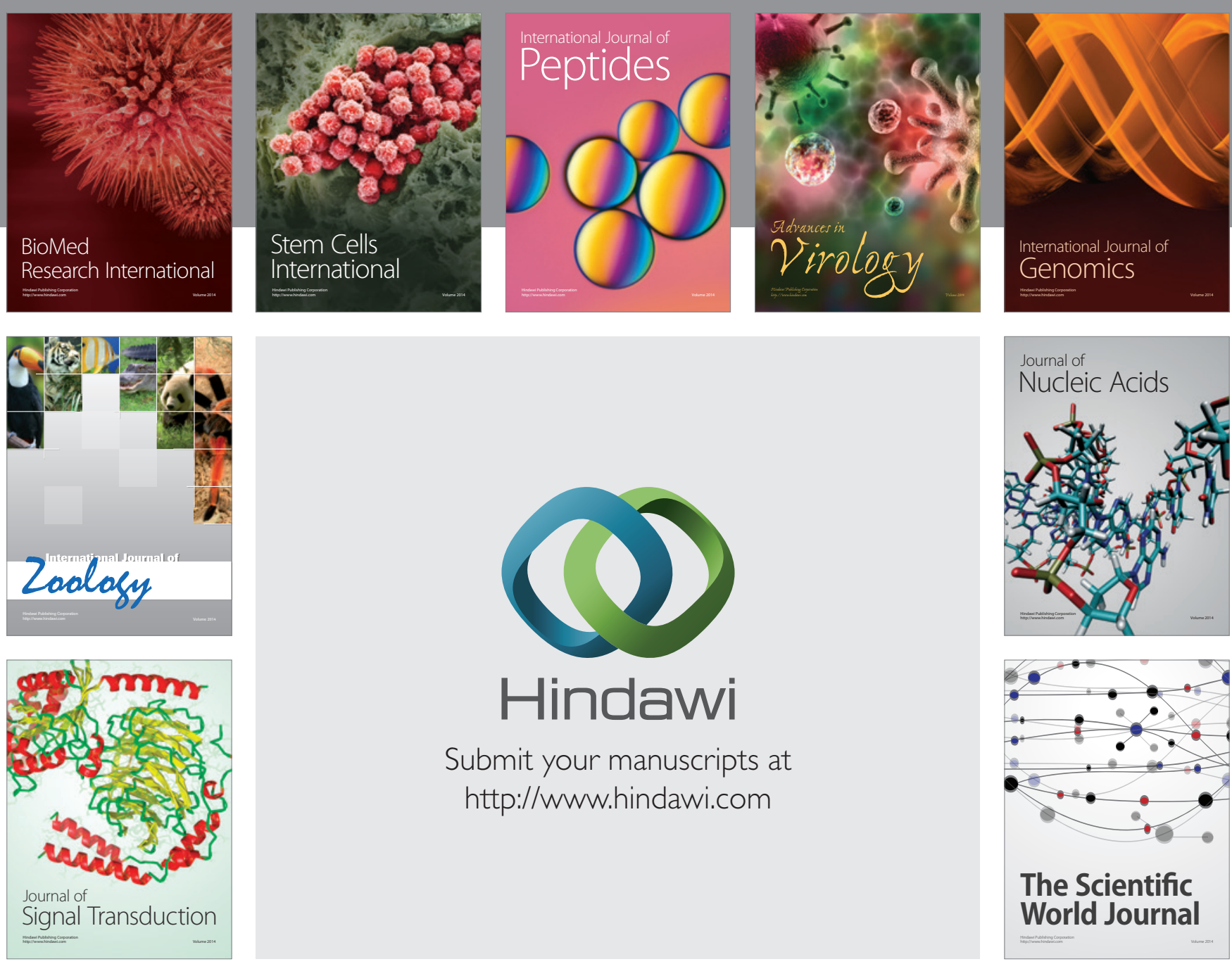

Submit your manuscripts at

http://www.hindawi.com
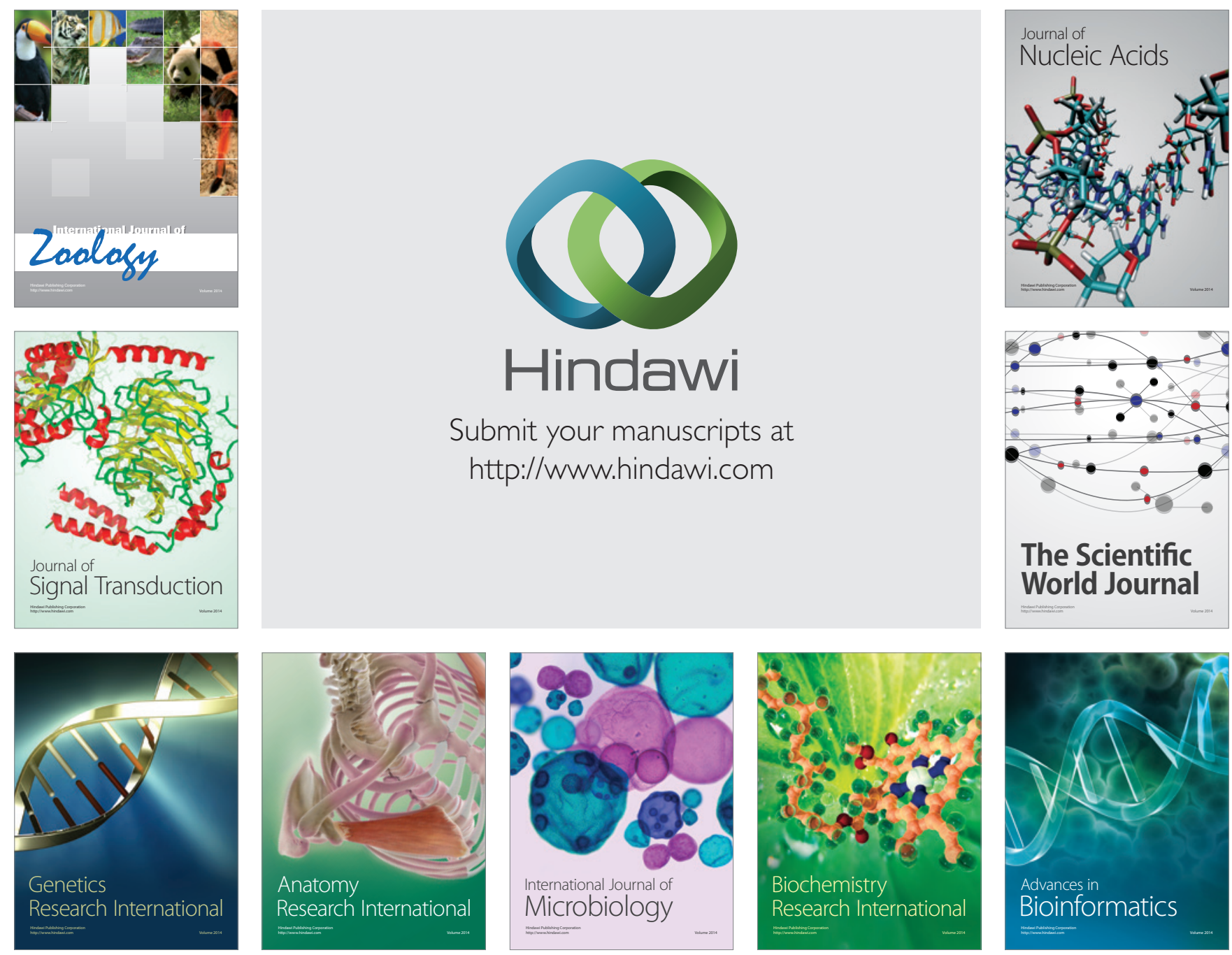

The Scientific World Journal
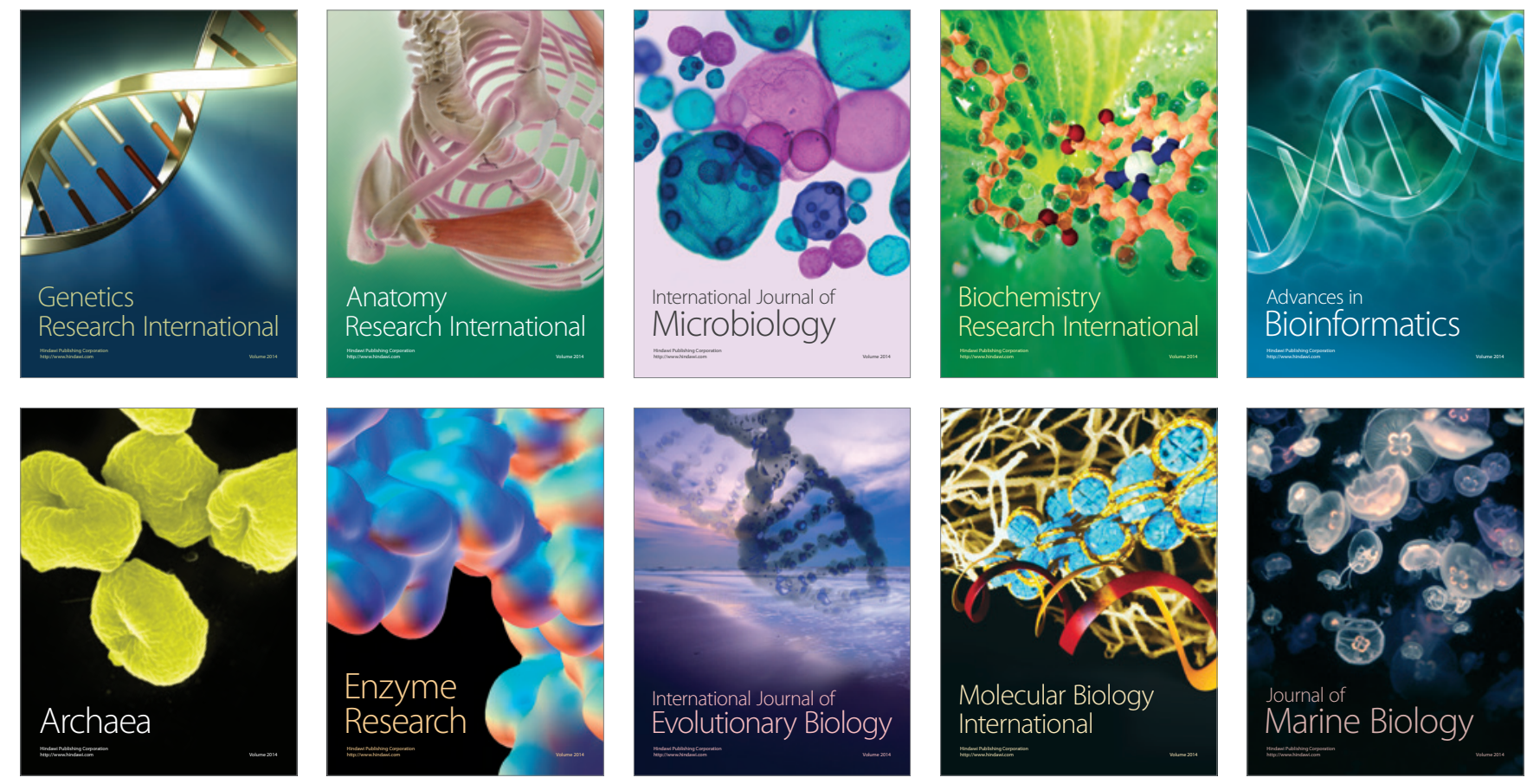